\title{
Drink Red: Phenolic Composition of Red Fruit Juices and Their Sensorial Acceptance
}

\author{
Alice Vilela and Fernanda Cosme * \\ Chemistry Research Centre-Vila Real (CQ-VR), Department of Biology and Environment, \\ School of Life Sciences and Environment, University of Trás-os-Montes and Alto Douro, \\ Edifício de Enologia, 5001-801 Vila Real, Portugal; avimoura@utad.pt \\ * Correspondence: fcosme@utad.pt; Tel.: +351-259-350-657; Fax: +351-259-350-480
}

Academic Editor: Laura Vázquez-Araújo

Received: 7 August 2016; Accepted: 21 October 2016; Published: 3 November 2016

\begin{abstract}
Consumers' food quality perception and sensorial experience are important in food consumption behavior and food choice. Red fruit juices are appreciated fruit juices for almost all consumers, due to their flavor and intense red color. Studies have also shown that their phytochemical composition, which is associated with their antioxidant activity, shows a protective effect against many chronic diseases. Nevertheless, the profile and concentration of anthocyanins are different in function of the fruit used; therefore, the color and health benefits of the juices also show differences. Some red fruit juices have lower concentrations of anthocyanins, for example strawberry, and others have higher concentrations, such as elderberry and black currant juices. High correlation was observed between antioxidant activity and red fruit juices' total anthocyanins concentration. Therefore, this review will addresses red fruit juices phenolic composition, with a special focus on the challenges for future, and some ideas on the sensory impact.
\end{abstract}

Keywords: red fruit juices; phenolic compounds; anthocyanins; antioxidant activity; sensorial analysis; consumer perception; sensorial acceptance

\section{General Introduction}

Red fruit juices have long been popular in Europe where the technology has been extensively developed for high value added fruits [1]. The documented phytochemical composition of red fruits is resulting in renewed global interest in industrial demand for these juices [2], since many red fruit juices, especially those that are naturally colorful, have high levels of antioxidants. Several researchers have concentrated their work on studying the formation of consumers' food quality expectations and sensorial experiences, as determinants of food acceptance [3,4]. Health issues can lead to the choice of red fruit juices and consequently to their acceptance and consumption [5]. Common fruits, such as berries, grapes, pomegranate, guava, sweetsop, persimmon and plum are rich in antioxidant phytochemicals [6-8] that have a protective role associated with their antioxidant activity, since overproduction of oxidants (reactive oxygen species and reactive nitrogen species) in the human body is involved in the pathogenesis of many chronic diseases [9], for instance, cardiovascular diseases, diabetes and cancers. It has been demonstrated that red-fruit juice grains wield a protective effect against the development of these diseases [10-12]. However, economic considerations limit but do not eliminate 100 percent red fruit products. The characteristic dominating flavor and color of these red fruits make them ideal for blending [13].

\section{Red Fruit Juices}

The market for non-alcoholic beverages is growing because consumers prefer healthier beverages. Nowadays, red fruit juices are known for their health benefits due to their higher phenolic compounds 
concentration, namely in flavonoid and non-flavonoid compounds, and consequently high antioxidant activity. The main flavonoid compounds in red fruits are anthocyanins (cyanidin and other colorings of the skin, for example in red grape, delphinidin, peonidin, malvidin, pelargonidin, petunidin), flavanols (proanthocyanidins and catechins), flavonols (derivatives of rutin, quercetin, myricetin and kaempferol). For non-flavonoid compounds, the main phenolic acids in red fruits are represented by hydroxylated derivatives of benzoic and hydroxycinnamic acid [14,15].

Within the red fruits used for the production of juices, pomegranate, red currant, blood orange, black currant, cherry, red raspberry, blackberry, strawberry, blueberry, elderberry and grape berries are amongst the richest in anthocyanins-water soluble pigments that contribute to the blue, purple, and red color in many fruits and their high antioxidant activity [16]. Numerous studies have shown that anthocyanins present a wide range of biological activities including antioxidant, anti-inflammatory, antimicrobial and anti-carcinogenic activities [17-19]. So, a high correlation has been shown between antioxidant activity and total anthocyanin concentration of red fruit juices [20]. However, anthocyanin stability depends on the existence of methoxyl or a hydroxyl group in the anthocyanin structure, giving them more or less stability and thus having an impact on their bioavailability. For example, delphinidin-3-glucoside has three hydroxyl groups in its B ring, being the most unstable anthocyanin, while malvidin-3-glucoside with more methoxyl groups is the most stable anthocyanin. Consequently, the biological activity of anthocyanins can also be influenced by glycosylation, which makes the anthocyanin more water soluble but less reactive to free radicals, subsequently decreasing their antioxidant activity [21].

For example, there is a motivation to produce red fruit beverages like grape juice or grape nectar for their important nutritional properties [22], such as antioxidant activity, due to the presence of phenolic compounds [23]. Grape juice is an unfermented beverage obtained from the dilution of grape pulp in water, with or without addition of sugars and acids [24]. Nevertheless, the existing juice processing technology leads to significant losses of these compounds through heating degradation and poor extraction from fruit. Therefore, consumers demand fresh, unpasteurized juices. According to Yuste et al. [25], in order to better preserve the properties of red fresh juices, research into alternative juice processing technology has been stimulated due to consumer demand for novel, natural and fresh-like beverages that are both safe and have improved nutritional and sensory characteristics. Manea [26] observed that the preservation of red fruit juices at refrigeration temperature conserves anthocyanins and tannins. Elderberry juice presented high concentration of anthocyanins, $0.84 \mathrm{~g} / \mathrm{L}$ and tannins $3.22 \mathrm{~g} / \mathrm{L}$. Elderberry and grapes have anthocyanins in the skin, however the ratio of the skin and pulp is lower in elderberry, consequently the elderberry juice will be more concentrated in anthocyanins than grape juice $(0.45 \mathrm{~g} / \mathrm{L})$. After three months of storage at refrigeration temperature, anthocyanin content decreased by $49.74 \%$ for grape juice and by $25.15 \%$ for the elderberry juice, since in the elderberry juice tannins were better preserved and act as antioxidants and preservatives, inhibiting juice enzymes that contributed to the protection of the anthocyanins; therefore juice color and flavor were better maintained [26]. So, novel treatments such as high hydrostatic pressure, high-intensity pulsed electric fields, and ultrasound are alternative treatments to pasteurization, in order to avoid the detrimental effects produced by high temperatures in the degradation of phenolic compounds as well as to be able to maintain the sensorial quality attributes of the final product $[27,28]$.

\section{Composition of Red Fruit Juices}

Grape nectar and beverages presented a different physicochemical composition to those from the grape juice, since they were obtained from a dilution of grape juice. Among the compounds that showed greater concentrations in grape juice are total soluble solids $\left(16.2^{\circ} \mathrm{Brix}\right)$, phenolic compounds, such as total polyphenol index $(65.8)$, anthocyanins $(283.7 \mathrm{mg} / \mathrm{L})$ and color intensity (1.245), organic acids, namely tartaric acid (6.7 g/L) and malic acid (3.3 g/L). Grape nectar and beverage are characterized by a higher ${ }^{\circ}$ Brix/titratable ratio, respectively 29.7 and 26.7 [23]. 
Red fruit juices' phenolic composition, namely total phenolic compounds and total anthocyanins ranged from $1234.27 \mathrm{mg} \mathrm{GAE} / \mathrm{L}$ to $6361.89 \mathrm{mg} \mathrm{GAE} / \mathrm{L}$, for red raspberry and elderberry, respectively, and the total anthocyanins ranged from $205.98 \mathrm{mgCGE} / \mathrm{L}$ to $4188.63 \mathrm{mgCGE} / \mathrm{L}$, for strawberry and elderberry, respectively [20]. Total anthocyanins were the main phenolic compounds presented in elderberry juice $(66 \%)$ or black currant juice $(56 \%)$ [20].

The antioxidant activity of red fruit juices ranged from 4.07 to $62.14 \mu \mathrm{mol} \mathrm{TE} / \mathrm{mL}$ for sweet cherry and elderberry, respectively [20], elderberry juice being the ones that have higher concentration in total phenolic compounds, total anthocyanins and consequently higher antioxidant activity. Red fruit juices showed considerable variations in anthocyanin content and profile as shown in Table 1. Some red fruit juices have low concentration of anthocyanins, such as strawberry, red raspberry and sweet cherry juice, while the concentration of these flavonoid compounds is high in elderberry and black currant juice.

Table 1. Anthocyanin profile from different red fruit juices. Adapted from [20,29-37].

\begin{tabular}{cl}
\hline Red Fruit Juice & \multicolumn{1}{c}{ Anthocyanin Profile } \\
\hline Strawberry & Cyanidin 3-glucoside, pelargonidin 3-glucoside, and pelargonidin 3-rutinoside \\
\hline Red raspberry & $\begin{array}{l}\text { Cyanidin 3-sophoroside, cyanidin 3-glucosyl-rutinoside, cyanidin 3-glucoside, } \\
\text { pelargonidin 3-sophoroside, and cyanidin 3-rutinoside }\end{array}$ \\
\hline Blackcurrant & $\begin{array}{l}\text { Delphinidin 3-glucoside, delphinidin 3-rutinoside, cyanidin 3-glucoside, cyanidin 3-rutinoside, and } \\
\text { delphinidin 3-rutinoside }\end{array}$ \\
\hline Blueberry & $\begin{array}{l}\text { Dephinidin 3-galactoside, delphinidin 3-glucoside, cyanidin 3-galactoside, } \\
\text { delphinidin 3-arabinoside, cyanidin 3-glucoside, petunidin 3-galactoside, cyanidin 3-arabinoside, } \\
\text { petunidin 3-glucoside, peonidin 3-galactoside, petunidin 3-arabinoside, peonidin 3-glucoside, } \\
\text { malvidin 3-galactoside, malvidin 3-glucoside, and malvidin 3-arabinoside }\end{array}$ \\
\hline Grapes & $\begin{array}{l}\text { Delphinidin 3-glucoside, cyanidin 3-glucoside, petunidin 3-glucoside, peonidin 3-glucoside and } \\
\text { malvidin 3-glucoside }\end{array}$ \\
\hline
\end{tabular}

Monomeric anthocyanins existing in red fruit juices were derivatives of cyanidin, delphinidin, pelargonidin, malvidin and peonidin. So, it is evident that juices produced with different red fruits, such as strawberry, raspberry, blueberry, black currant and grapes, differ in the quantity and type of anthocyanins. The family of European Vitis vinifera vines is characterized by anthocyanins, which have only one molecule of glucose, while non-vinifera vines such as Vitis labrusca or Vitis rotundafolia grapes and American hybrids have anthocyanins with two molecules of glucose. Obón et al. [29], Lopes da Silva et al. [30], Jakobek et al. [20] and Stój et al. [31] determined in strawberry juices the existence of cyanidin 3-glucoside, pelargonidin 3-glucoside, and pelargonidin 3-rutinoside, the major anthocyanin in this juice being pelargonidin 3-glucoside (Table 1). The anthocyanin profile from red raspberry juices showed five anthocyanins, namely cyanidin 3-sophoroside, cyanidin 3-glucosyl-rutinoside, cyanidin 3-glucoside, pelargonidin 3-sophoroside, and cyanidin 3-rutinoside [29,31,32]. Blackcurrant juices are characterized by monomeric anthocyanins such as delphinidin 3-glucoside, delphinidin 3-rutinoside, cyanidin 3-glucoside, cyanidin 3-rutinoside, and delphinidin 3-rutinoside [29,32-34]. Pelargonidin-3-glucoside and cyanidin-3-xylorutinoside were the main anthocyanins in strawberry and red currant juices, respectively. Those anthocyanins were not detected in raspberry and black currant juices, in which cyanidin-3-sophoroside as well as delphinidin-3-rutinoside and cyanidin-3-rutinoside were the main anthocyanins, respectively [31]. Blueberry juices anthocyanin profile studied by several authors [29,32,35-37], showed fourteen different anthocyanins, namely dephinidin 3-galactoside, delphinidin 3-glucoside, cyanidin 3-galactoside, delphinidin 3-arabinoside, cyanidin 3-glucoside, petunidin 3-galactoside, cyanidin 3-arabinoside, petunidin 3-glucoside, peonidin 3-galactoside, petunidin 3-arabinoside, peonidin 3-glucoside, malvidin 3-galactoside, malvidin 3-glucoside, and malvidin 3-arabinoside (Table 1). Grape juice anthocyanins are mainly delphinidin 3-glucoside, cyanidin 3-glucoside, petunidin 3-glucoside, peonidin 3-glucoside and malvidin 3-glucoside [32,37]. According to Jakobek et al. [20], elderberry, blackberry and sour cherry juice are characterized 
by cyanidin derivatives, whereas black currant juice by delphinidin and cyanidin derivatives and strawberry juice are characterized by pelargonidin derivatives. Table 1 showed that each red fruit juice possesses a unique anthocyanin profile. Although all red fruit juices are good sources of bioactive phytochemicals, elderberry and black currant juices stand out in higher anthocyanin concentration and consequently have higher antioxidant activities [20].

\section{Color and Flavor Perception vs. Consumer Acceptance}

There is no color without light, nor is there color perception without a sensory organ and brain to process visual input. Our visual perceptions are initiated and influenced by the anatomical structure of the eye. The cornea and lens, on the eye, act together like a camera lens to focus an image of the visual world on the retina, at the back of the eye, which acts like the film of a camera. An image is formed, upside down, on the retina—a structure less than $0.5 \mathrm{~mm}$ thick (Figure 1) [38,39]—with light rays converging most at the cornea and upon entering and exiting the lens [40].

The human retina contains two types of photoreceptors, rods and cones. Cones are involved in color vision, while rods are stimulated by weak light like moonlight. The photoreceptors synapse on layer upon layer of interneurons that are innervated by different combinations of photoreceptor cells. All these signals are processed and interpreted by the part of the brain called the visual cortex [41].

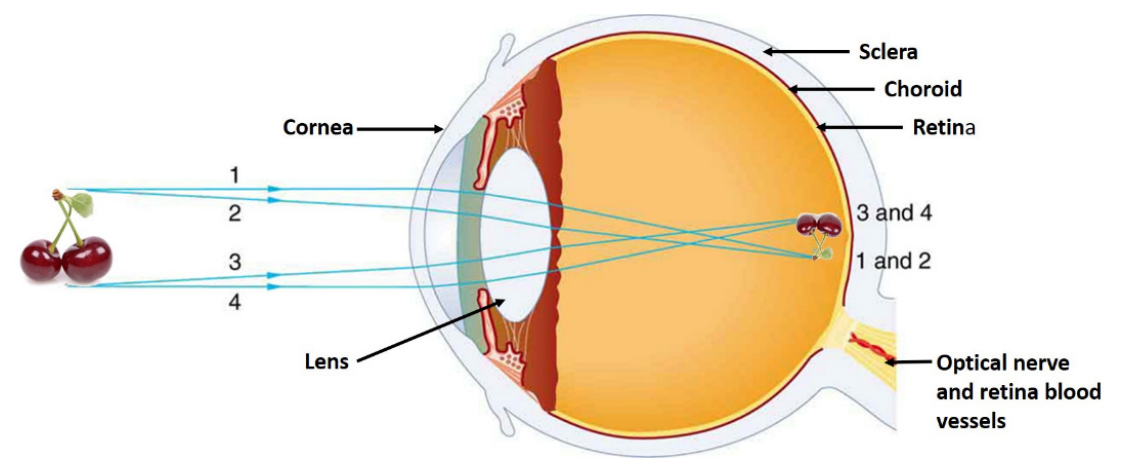

Figure 1. Schematic diagram of the human eye and image formation on the retina. Rays from the top and bottom of the object (1 and 2; 3 and 4) are traced and produce an inverted real image on the retina. The distance to the object is drawn smaller than scale. Adapted from [42].

Color is the single most important product-intrinsic sensory cue when it comes to setting people's expectations regarding the likely taste and flavor of food and drink. The color of food is an often ignored sensory attribute that can really change consumers' aroma/flavor perception. A growing body of scientific research now suggests that our experience of taste and flavor is determined to a large degree by the expectations that we generate (often automatically) prior to tasting [43]. Under most everyday conditions, consumers have the opportunity to inspect food and drink visually before deciding on whether or not to buy or taste it. As Roth et al. [44] mentioned in their work, when food colors are different from the expected norm, flavor identification is decreased, the color-flavor association becomes stronger, and color has a greater effect on liking of the food [44]. Consumers associate certain colors with certain flavors, so it is important for food manufacturers to have the expected color in their food. Color and appearance of food create expectations that affect how we feel and behave [45], and influence food identification [46]. This occurs in simple foods and in complex foods in which there are multiple taste stimuli. For example, when white wine is colored red, the tendency is to describe the wine using red wine odor terms instead of the white wine odor terms that are instinctively used in white wine [47]. As such, food color can be considered the most important product-intrinsic sensory cue leading the sensory and hedonic expectations that the consumer holds concerning the foods and drinks that they search for, purchase, and that they may subsequently consume [48]. 
Therefore, it is not surprising that the colors sector of the food industry has become very important. Color producing companies are high-tech and sophisticated and their main objective is naturalness. Besides the juice industry, red fruit juices have also been used to enhance or change the color of different food recipes [49]. According to this author, red fruit juices behave in different circumstances. In mixtures of water, soy milk and yoghurt, each made with $10 \%$ juice, it was noticed that each juice changed color as a reaction to such things as $\mathrm{pH}$ or presence of proteins. Anthocyanins can change from bright red to blue depending on the $\mathrm{pH}$ (Figure 2) [49].

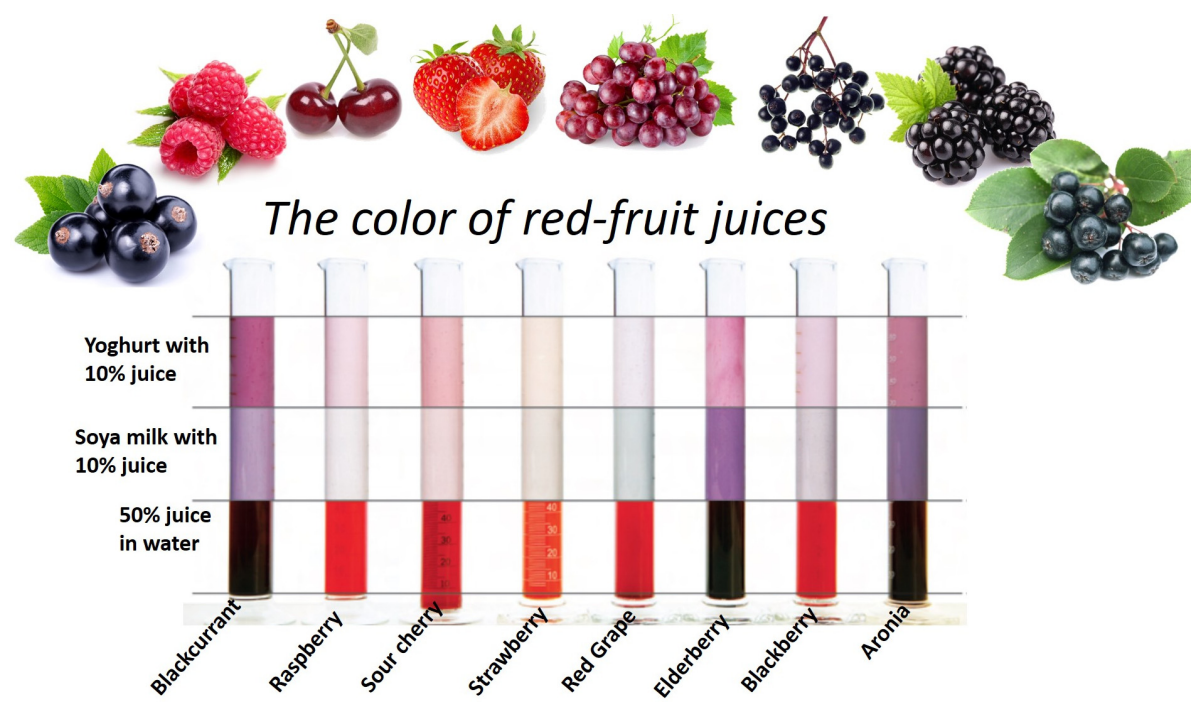

Figure 2. The color of different flavored juices made with $90 \%$ yoghurt, $90 \%$ soy milk and $50 \%$ water, as a reaction to $\mathrm{pH}$ and/or presence of protein. Adapted from [49].

The best juices to use as coloring agents are blackcurrant (Ribes nigrum), elderberry (Sambucus niger) and aronia (Aronia melanocarpa) (Figure 2). However, the taste of blackcurrant is very strong and, as such, elderberry and aronia are used in cases where fruit flavor would be not required [49].

Consumers often confuse tastes with flavors. Taste perception refers to those sensations that are elicited by the stimulation of the gustatory receptors on the tongue-sweet, sour, salty, bitter, umami and fat taste [50]. Humans, usually, never experience pure tastants in isolation. We mostly experience flavors, resulting from the combination of taste, retronasal olfaction (referred to as 'mouth smell', in contrast to orthonasal olfaction or 'sniffing', Figure 3) and trigeminal inputs. 'fruity', 'meaty', 'floral' and 'burnt' are all flavor descriptors [51].
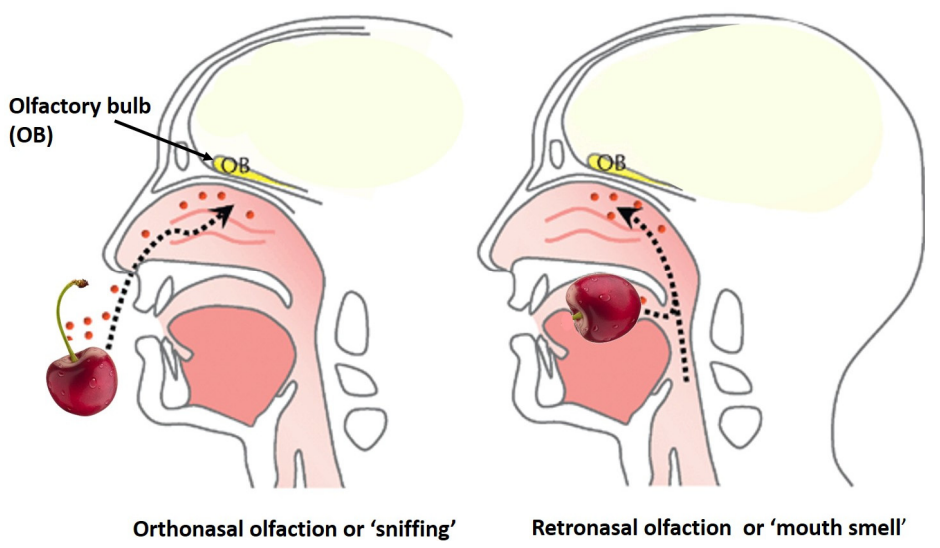

Figure 3. Orthonasal olfaction or 'sniffing' in contrast to retronasal olfaction, occasionally referred to as 'mouth smell'. 
Smell (both orthonasal and retronasal) often combines with taste to enhance our perception of flavor [51]. A study performed by Dalton et al. [52] demonstrated that the ability to detect threshold levels of benzaldehyde (almond-like aroma) sniffed in solution could be intensely enhanced by placing a subthreshold drop of saccharin on the tongue.

One important aspect of food consumption that, sadly, is often over-looked, is that consumers want to enjoy their food. In fact, many foods are consumed almost entirely for the pleasure value they impart [53]. Since childhood, our behavior towards foods seems to be strongly influenced by the effects of taste and flavor. Steiner [54], in 1979, studied the facial expressions of young babies when given solutions of sweet and bitter compounds (Figure 4) the infant reacted in very different ways. Sweet tastes elicited a facial acceptance response, but, bitter tastes, gave a very different response, with tight closing of the eyes, gaping mouth and sudden turn of the head [54]. These inborn reactions of young babies are indicative of a basic survival instinct in all of us. Some of these early pre-dispositions tend to remain with us throughout life. We all like sweets and pleasant smells! However, some other food preferences (liking for 'bitter' tasting lagers or hot spicy foods) demonstrate a degree of acquired liking [53].

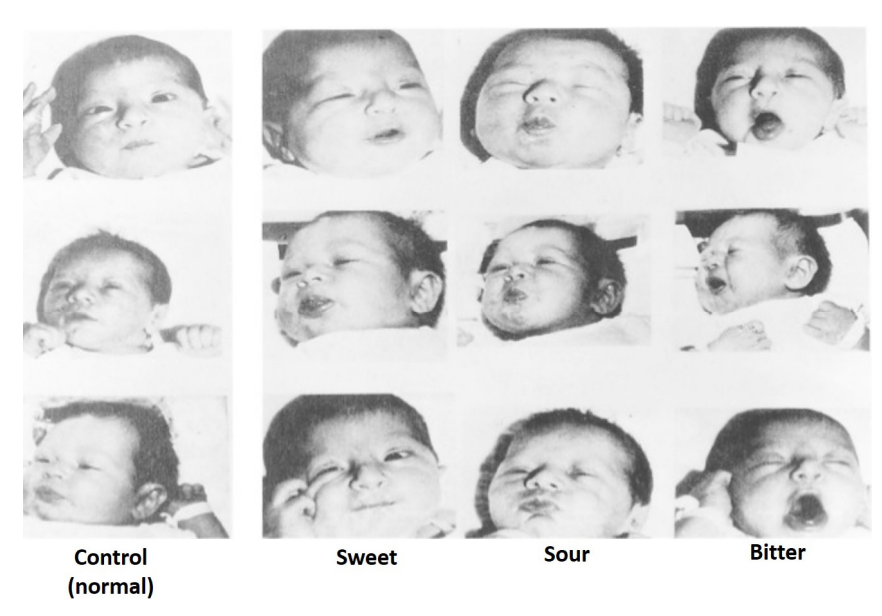

Figure 4. Taste responses to sweet, sour and bitter taste in newborns. Adapted from [54].

Studies have demonstrated that changing the color (both the hue and the intensity) can change the perceived flavor and the intensity of the taste [55]. Thus, the flavor perception in food is influenced by color. Red food coloring also appears to be a particularly good inducer of sweetness. It seems that we may have internalized the environmental association between sweetness and redness in ripe fruits [51].

Stevenson [56] has demonstrated that whether or not a given color, added to a food or beverage, affects a person's taste/flavor perception largely depends on the meaning that the person associates with foods and drinks having that color. In an experiment conducted in UK among young consumers, it was shown that they expected that a drink colored blue would have a raspberry-like taste/flavor. Taiwanese young consumers expect that such a drink would present a mint taste/flavor [56]. Therefore, one needs to know what expectations a consumer has in order to predict what it is they will likely experience when a particular color is added to a given food or drink [51]. If the expectation and the experience are not too different from one another, for instance, expecting blackcurrant, while getting blackberry, then the consumer will likely report experiencing the 'expected' flavor [51].

Despite growing demand by consumers for healthy beverages, artificial colors are still widely used. Red drinks' labels generally conformed to the requirements of the law, but food product labels can often be misleading to consumers about the real characteristics of the product. Fallico et al. [57] determined by HPLC with UV-Vis detection, the anthocyanins levels of, and artificial colors in, red orange juices and other red beverages. They found that red juice-based drinks, containing from $0 \%$ to 
$30 \%$ of red orange, berry, grape or pomegranate juices, had low levels of anthocyanins $(7 \mathrm{mg} / \mathrm{L})$ and high levels of E129 (Allura Red AC, a red azo dye) $(32 \mathrm{mg} / \mathrm{L}$ ), which were responsible for about $90.7 \%$ of the color of these beverages. Red health drinks, enriched with vitamins and polyphenols, contained from 3\% to $50 \%$ of red fruit juices, but, in this case, the E129 levels were also higher than anthocyanins (about $22 \mathrm{mg} / \mathrm{L}$ and $9 \mathrm{mg} / \mathrm{L}$, respectively), and were responsible for $76.1 \%$ of the beverages' color. They found no correlation between the level of anthocyanins and the declared percentage of red fruits, although all of the beverages claimed to contain red fruits on the labels.

\section{Off Flavors Associated with Red Fruit Juices}

\subsection{Off Odors}

The volatile composition of fruit flavors is extremely complex, and non-characterizing volatile esters are common across species. However, trace sulfur volatiles have been identified which play significant roles in the flavor of grapefruit, strawberry, and other fruits. An assembling of character-impact sulfur compounds in red fruit flavors is summarized in Table 2 according to McGorrin [58].

Table 2. Character-impact sulfur compounds in red fruits.

\begin{tabular}{cccc}
\hline Character Impact Compound & Odor Description & Occurrence & Reference \\
\hline 4-Methoxy-2-methyl-2-butanethiol & Blackcurrant sulfur & Blackcurrant & {$[59]$} \\
8-Mercapto- $p$-menthan-3-one & Blackcurrant catty & Blackcurrant (synthetic) & {$[60]$} \\
4-Mercapto-4-methyl-2-pentanone & Cat urine & Sauvignon grape & {$[61]$} \\
Ethyl-3-mercaptopropionate & Fresh grape foxy & Concord grape & {$[62]$} \\
Methyl thioacetate & Cheesy garlic & Strawberry & {$[63]$} \\
Methyl thiobutanoate & Cheesy cabbage & Strawberry & {$[63]$} \\
\hline
\end{tabular}

Blackcurrant flavor is popular in Europe, and is associated with numerous health-related functional foods. The key aroma component in blackcurrant is 4-methoxy-2-methyl-2-butanethiol [60]. The catty flavor of blackcurrant (Ribes nigrum) was earlier attributed to cat ketone, but it was later shown to be absent during flavor and sensory analysis of blackcurrant juice concentrates [64]. The 2-methyl-3-furanthiol cooked meat-like aroma was among the five most powerful aroma compounds identified by GC-olfactometry in blackcurrant juice [65]. The flavor of 8-mercapto- $p$-menthan-3-one contributes to a powerful blackcurrant, cassis and catty-like aroma character, however it is a synthetic aroma, synthesized by reaction of hydrogen sulfide with (-)-pulegone from buchu leaf oil, and has not been identified in the natural blackcurrant fruit [59].

Molds, yeasts, and bacteria can cause spoilage and the occurrence of off-odors in fruit juices. Microbial contamination, most times due to fruit's injury during transport and storage, can cause off flavor's occurrence, produced by flavor- and odor-active metabolites of the involved microorganisms [66,67]. The most commonly encountered microbial genera are Acetobacter, Alicyclobacillus, Bacillus, Clostridium, Gluconobacter, Lactobacillus, Leuconostoc, Saccharobacter, Zymomonas, and Zymobacter. Nevertheless, yeasts are predominant because of their high acid tolerance and the ability of many of them to grow anaerobically. Candida, Pichia, Rhodotorula, and Saccharomyces are the genera mainly involved in spoiled juices; Brettanomyces intermedius, Candida maltosa, C. sake, Dekkera bruxellensis, D. naardenensis, Hanseniaspora guilliermondii, Pichia membranifaciens, Saccharomyces bailii, S. bisphorus, S. cerevisiae, S. rouxii, S. bayanus, Schizosaccharomyces pombe, Schwanniomyces occidentals, Torulopsis holmii, Torulaspora delbruckii, and Zygosaccharomyces microellipsodes are the species most frequently isolated [68]. According to Bevilacqua [68] the main microorganisms related to spoilage in fruit juices are: Highly fermentative yeasts (production of ethanol and $\mathrm{CO}_{2}$ from sugars, formation of biofilm, bulging or exploding of containers); Acetobacter and Gluconobacter bacteria (oxidation of ethanol, fermentation and turbidity); Lactobacillus, Leuconostoc lactic acid bacteria (sour or off-taste, buttermilk off-flavor, gummy slime or ropiness, production of acetic acid, $\mathrm{CO}_{2}$ and ethanol); Clostridium spp. (production of gas, a strong butyric odor, and increased acidity); A. acidoterrestris (phenolic or antiseptic odor or off-flavor 
with or without light sediment or slight haze); Bacillus spp. (flat sour); Zymomonas, Saccharobacter and Zymobacter (ethanol production) and heat resistant molds that cause off-flavor or odor like "stale" or "old", development of a mycelial mat, reduction in sugar content and mycotoxin production.

As it was mentioned before, spore-former bacteria like Alicyclobacillus, Bacillus, and Clostridium are also found in fruit juices [69]. These microorganisms are very resistant against high temperatures and low $\mathrm{pH}$ values surviving the pasteurization process in the acidic environment of fruit juices [70]. Due to their behavior, they are frequently called thermoacidophilic bacteria. In addition, they may germinate and grow in the shelf-stable product causing a distinct off-flavor after a certain storage period of the product on the shelf [71].

Siegmund and Pöllinger-Zierler [69], is represented a list of metabolites responsible for off-odors in juices caused by the growth of Alicyclobacillus acidoterrestris and Streptomyces ssp. The first produces metabolites like $m$-anisaldehyde musty, $o$-anisaldehyde, $p$-anisaldehyde, 2-isobutyl-3-methoxypyrazine, 2-isopropyl-3-methoxypyrazine, 2,3-dimethylpyrazine, [(1S)-endo]-(-)-borneol and 2-methylisoborneol. These compounds imprint to the wine medicinal, pungent, sweet, chemical, floral, marzipan, sweet, green pepper, green, acrid, parsley and herbaceous (cut grass) odors. Alicyclobacillus acidoterrestris produces guaiacol and dibromophenol wish give the wine medicinal, sweet, chemical, medical office and smoky, pungent, medicinal, dental office odors, respectively.

\subsection{Bitterness and Astringency}

Plants protect themselves against being eaten by secreting natural pesticides and other toxins [72]. Plant-based phenols, flavonoids, isoflavones, terpenes, and glucosinolates are practically always bitter and astringent [73], and although potentially beneficial to human health in small doses, many such compounds are toxic [74]. In addition to their bactericidal or biological activity [75], these substances may provide a defense against predators by making the plant unpalatable [73]. Humans reject foods that are perceived to be excessively bitter [76]. The food industry routinely removes phenols and flavonoids, isoflavones, terpenes, and glucosinolates from plant foods through selective breeding and a variety of "debittering" processes [76,77]. Many of the bioactive phytonutrients currently studied in the laboratory have long been treated by industry and consumers alike as disposable bitter waste [76].

Abnormal bitterness tends to be equated with dietary danger, and rightly so. Rancid fats, hydrolyzed proteins, plant-derived alkaloids, and other toxins generally have an unpleasant bitter taste [70]. Microbial fermentation also results in bitter-tasting compounds [70]. Given the wide distribution of plant-based bitter toxins, past efforts to develop less bitter cultivars of common plant foods may have been driven not so much by taste as by safety concerns [76].

In relation with red fruit juices, all the manufacturing steps in juice production have effects on the chemical composition and sensory properties of the end products [78]. For example, treatment with heat and enzymes frequently results in changes in the aroma profile of blackcurrant juices [79], and enzyme-aided juice processing increases astringency and bitterness [80]. Blackcurrant squash products with a high content of juice are often perceived as being bitter and astringent [81], properties, as we have already mentioned, regarded as negative attributes of foods [76]. Consumers always choose by food taste and are not willing to compromise the taste for health properties [82].

\section{Taste and Flavor Modification Techniques}

Blackcurrant juices are often sweetened with sugars or other added sweeteners to reduce sourness and astringency [83]. However, addition of sugars compromises the health effects of the juices, making it less attractive for consumers with health issues. Diluting the juice with water and mixing with other fruits are alternative ways often applied to improve the sensory properties of the final product. Optimal selection of cultivars and processing techniques could minimize the need of dilution, sweetening and other types of modification [84].

Laaksonen and co-workers [84] compared the composition and sensory properties of juices extracted, at laboratory scale, from berries of different blackcurrant cultivars by different processes. 
The cultivars used were Mortti, Mikael, Marski, Ola and a new breed no. 15 (Breed15) of blackcurrant cultivated in Southern Finland. Two processing methods were applied to press juices from berries of each cultivar: a non-enzymatic pressing and an enzyme-aided juice pressing. Both juice-processing technologies and cultivars significantly affect the chemical composition and sensory quality of blackcurrant juice. Enzyme-aided juice pressing led to increased juice yield, with higher content of phenolic compounds increasing the intensities of astringency and bitterness and adversely affecting the sensory properties of the juices when compared with non-enzyme pressing [84]. Therefore, non-enzyme pressing provides an alternative processing technology to produce juices of more pleasant sensory profiles. Moreover, non-enzymatic processing can be considered as an alternative processing technology to produce more natural products, including juices with more pleasant sensory profiles. Non-enzyme pressing reduces the need of modification (dilution and blending) of the end products with less addition of sugars or other sweeteners. This process may also be used to produce raw material for non-juice products such as purees and smoothies. Due to the low yield, efficient use of non-enzymatic juice processing requires innovative exploitation methods for press residues [84].

Development and production of natural berry products with the ideal sensory properties for various consumer groups still remains a challenge for the food industry. Recently Laaksonen et al. [85], in a study with the blackcurrant cultivar 'Mortti', found that the press residue from the non-enzyme-aided pressing can be further pressed by an enzyme-aided process to produce polyphenol-rich juice with a fermented, juice-type aroma profile that is well accepted by the consumers. The new juice concepts studied after process optimization could be commercialized, providing alternative products for various consumer groups. The processes may be extended to the processing of other berries to increase the consumption of berries as a part of healthy diet.

\section{Final Remarks}

Over the last years there have been many changes in the juice beverage market as consumers search for new benefits from their juices. As a result, an increase in demand occurred for red fruit juices, which could be considered as healthy fruit beverages due to their high phenolic content, specifically anthocyanins, which are extracted from the fruits during processing. Therefore, these red fruit juices could be used to design or develop new products that meet consumers' requests. However, consumer acceptance of these new developed products must be also evaluated.

Author Contributions: Alice Vilela and Fernanda Cosme equally contributed to the paper.

Conflicts of Interest: The authors declare no conflict of interest.

\section{References}

1. IBISWorld. Global Fruit \& Vegetables Processing; Industry Report; IBISWorld: Melbourne, Australia, 2016; p. 38.

2. Hakkinen, S.; Heinonen, M.; Karenlampi, S.; Mykkanen, H.; Ruuskanen, J.; Torronen, R. Screening of selected flavonoids and phenolic acids in 19 berries. Food. Res. Int. 1999, 32, 345-354. [CrossRef]

3. Asp, E.H. Factors affecting food decisions made by individual consumers. Food Policy 1999, 24, 287-294. [CrossRef]

4. Bell, R.; Marshall, D.W. The construct of food involvement in behavioral research: Scale development and validation. Appetite 2003, 40, 235-244. [CrossRef]

5. Delaney, M.; McCarthy, M. Food choice and health across the life course: A qualitative study examining food choice in older Irish adults. In Proceedings of the 113th EAAE Seminar "A Resilient European Food Industry and Food Chain in a Challenging World", Chania, Crete, Greece, 3-6 September 2009.

6. Xia, E.Q.; Deng, G.F.; Guo, Y.J.; Li, H.B. Biological activities of polyphenols from grapes. Int. J. Mol. Sci. 2010, 11, 622-646. [CrossRef] [PubMed]

7. Fu, L.; Xu, B.T.; Xu, X.R.; Gan, R.Y.; Zhang, Y.; Xia, E.Q.; Li, H.B. Antioxidant capacities and total phenolic contents of fruits. Food Chem. 2011, 129, 345-350. [CrossRef]

8. Manganaris, G.A.; Goulas, V.; Vicente, A.R.; Terry, L.A. Berry antioxidants: Small fruits providing large benefits. J. Sci. Food Agric. 2014, 94, 825-833. [CrossRef] [PubMed] 
9. Zhang, Y.J.; Ga, R.Y.; Li, S.; Zhou, Y.; Li, A.N.; Xu, D.P.; Li, H.B. Antioxidant phytochemicals for the prevention and treatment of chronic diseases. Molecules 2015, 20, 21138-21156. [CrossRef] [PubMed]

10. Kyro, C.; Skeie, G.; Loft, S.; Landberg, R.; Christensen, J.; Lund, E.; Nilsson, L.M.; Palmqvist, R.; Tjonnelan, A.; Olsen, A. Intake of whole grains from different cereal and food sources and incidence of colorectal cancer in the Scandinavian HELGA cohort. Cancer Causes Control 2013, 24, 1363-1374. [CrossRef] [PubMed]

11. Mursu, J.; Virtanen, J.K.; Tuomainen, T.P.; Nurmi, T.; Voutilainen, S. Intake of fruit, berries, and vegetable and risk of type 2 diabetes in Finnish men: The kuopio ischaemic heart disease risk factor study. Am. J. Clin. Nutr. 2014, 9, 328-333. [CrossRef] [PubMed]

12. Kruk, J. Association between vegetable, fruit and carbohydrate intake and breast cancer risk in relation to physical activity. Asian Pac. J. Cancer Prev. 2014, 15, 4429-4436. [CrossRef] [PubMed]

13. Bates, R.P.; Morris, J.R.; Crandall, P.G. Principles and Practice of Small and Medium Scale Fruit Juice Processing; FAO Agricultural Services Bulletin; Food and Agricultural Organization: Rome, Italy, 2001; Volume 146.

14. Prior, R.; Cao, G.; Martin, A.; Sofic, E.; McEwen, J.; O’Brien, C.; Lischner, N.; Ehlenfeldt, M.; Kalt, W.; Krewer, G.; et al. Antioxidant capacity as influenced by total phenolic and anthocyanin content, maturity, and variety of Vaccinium species. J. Agric. Food Chem. 1998, 46, 2686-2693. [CrossRef]

15. Kalt, W.; Forney, C.F.; Martin, A.; Prior, R.L. Antioxidant capacity, vitamin C, phenolics, and anthocyanins after fresh storage of small fruits. J. Agric. Food Chem. 1999, 47, 4638-4644. [CrossRef] [PubMed]

16. Garcia-Herrera, P.; Perez-Rodriguez, M.-L.; Aguilera-Delgado, T.; Labari-Reyes, M.-J.; Olmedilla-Alonso, B.; Camara, M.; Pascual-Teresa, S. Anthocyanin profile of red fruits and black carrot juices, purees and concentrates by HPLC-DAD-ESI/MS-QTOF. Int. J. Food Sci. Technol. 2016, 51, 2290-2300. [CrossRef]

17. De Pascual-Teresa, S.; Sánchez-Ballesta, M.T. Anthocyanins: From plant to health. Phytochem. Rev. 2008, 7, 281-299. [CrossRef]

18. Mazza, G.J. Anthocyanins and heart health. Annali dell Istituto Superiore di Sanita 2007, 43, 369-374. [PubMed]

19. Wang, L.; Stoner, G.D. Anthocyanins and their role in cancer prevention. Cancer Lett. 2008, 269, $281-290$. [CrossRef] [PubMed]

20. Jakobek, L.; Serugi, M.; Medvidovic-Kosanovic, M.; Novak, I. Anthocyanin contente and antioxidante activity of various fruit juices. Deutsche Lebensmitlel-Rundschau 2007, 2, 58-64.

21. Rice-Evans, C.A.; Miller, N.J.; Paganga, G. Antioxidant properties of phenolic compounds. Trends Plant Sci. 1997, 2, 152-159. [CrossRef]

22. Burin, V.M.; Falcão, L.D.; Gonzaga, L.V.; Fett, R.; Rosier, J.P.; Bordignon-Luiz, M.T. Colour, phenolic content and antioxidant activity of grape juice. Ciência E Tecnologia De Alimentos 2010, 30, 1027-1032. [CrossRef]

23. Rizzon, L.A.; Mielle, A. Analytical characteristics and discrimination of Brazilian commercial grape juice, nectar, and beverage. Ciência E Tecnologia De Alimentos 2012, 32, 93-97. [CrossRef]

24. Voorpostel, C.R.; Dutra, M.B.L.; Bolini, H.M.A. Sensory profile and drivers of liking for grape néctar among smoker and nonsmoker consumers. Food Sci. Technol. 2014, 34, 164-173. [CrossRef]

25. Yuste, J.; Fung, D.Y.C.; Thompson, L.K.; Crozier-Dodson, B.A. Combination of Carbon Dioxide and Cinnamon to Inactivate Escherichia coli O157:H7 in Apple Juice. J. Food Sci. 2002, 67, 3087-3090. [CrossRef]

26. Manea, J. Evolution of bioactive compounds in fruit juices during preservation by refrigeration. Rev. Roum. Chim. 2013, 58, 619-622.

27. Plaza, L.; Sánchez-Moreno, C.; Elez-Martínez, P.; de Ancos, B.; Martín-Belloso, O.; Cano, M.P. Effect of refrigerated storage on vitamin $C$ and antioxidant activity of orange juice processes by high-pressure or pulsed electric fields with regard to low pasteurization. Eur. Food Res. Technol. 2006, 223, 487-493. [CrossRef]

28. Kamal, R.A.; Romika, D.; Neeraj, K.A.; Ashish, A. Emerging preservation techniques for controlling spoilage and pathogenic microorganisms in fruit juices. Int. J. Food Microbiol. 2014, 2014, 758942.

29. Obón, J.M.; Díaz-García, M.C.; Castellar, M.R. Red fruit juice quality and authenticity control by HPLC. J. Food Comp. Anal. 2011, 24, 760-771. [CrossRef]

30. Da Silva, F.L.; Escribano-Bailón, M.T.; Alonso, J.J.P.; Rivas-Gonzalo, J.C.; Santos-Buelga, C. Anthocyanin pigments in strawberry. LWT-Food Sci. Technol. 2007, 40, 374-382. [CrossRef]

31. Stój, A.; Malik, A.; Targoński, Z. Comparative analysis of anthocyanin composition of juices obtained from selected species of berry fruits. Pol. J. Food Nutr. Sci. 2006, 15, 401-407.

32. Goiffon, J.P.; Mouly, P.P.; Gaydou, E.M. Anthocyanic pigment determination in red fruit juices, concentrated juices and syrups using liquid chromatography. Anal. Chim. Acta 1999, 382, 39-50. [CrossRef] 
33. Bermúdez-Soto, M.J.; Tomás-Barberán, F.A. Evaluation of commercial red fruit juice concentrates as ingredients for antioxidant functional juices. Eur. Food Res. Technol. 2004, 219, 133-141. [CrossRef]

34. Rubinskiene, M.; Jasutiene, I.; Venskutonis, P.R.; Viskelis, P. HPLC determination of the composition and stability of blackcurrant anthocyanins. J. Chromatogr. Sci. 2005, 43, 478-482. [CrossRef] [PubMed]

35. Prior, R.L.; Lazarus, S.A.; Cao, G.; Muccitelli, H.; Hammerstone, J.F. Identification of procyanidins and anthocyanins in blueberry and cranberries (Vaccinium spp.) using high performance liquid chromatography/mass spectrometry. J. Agric. Food Chem. 2001, 49, 1270-1276. [CrossRef] [PubMed]

36. Versari, A.; Barbanti, D.; Biesenbruch, S.; Farnell, P.J. Analysis of anthocyanins in red fruits by use of HPLC/spectral array detection. Ital. J. Food Sci. 1997, 9, 141-148.

37. Wu, X.; Prior, R. Systematic identification and characterization of anthocyanins by HPLC-ESI-MS/MS in common fruits in the United States: Fruits and berries. J. Agric. Food Chem. 2005, 53, 2589-2599. [CrossRef] [PubMed]

38. Lennie, P. The physiology of color vision. In The Science of Color; Elsevier: Amsterdam, The Netherlands, 2003; pp. 217-246.

39. Kolb, H. Simple Anatomy of the Retina. The Organization of the Retina and Visual System. Webvision 2011. Available online: http://webvision.med.utah.edu/book/part-i-foundations/simple-anatomy-of-the-retina/ (accessed on 19 July 2016).

40. Fairchild, M.D. Humam color vision. In Color Appearance Models, 2nd ed.; John Wiley \& Sons: Hoboken, NJ, USA, 2005; pp. 1-34.

41. Lodish, H.; Berk, A.; Zipursky, S.L.; Matsudaria, P.; Baltimore, D.; Darnell, J. Sensory transduction. In Molecular Cell Biology, 4th ed.; W.H. Freeman: New York, NY, USA, 2000.

42. Openstax. Physics of the Eye. 2016. Available online: http://cnx.org/contents/edFYqrQm@3/Physics-ofthe-Eye (accessed on 19 July 2016).

43. Piqueras-Fizman, B.; Spence, C. Sensory expectations based on product-extrinsic food cues: An interdisciplinary review of the empirical evidence and theoretical accounts. Food Qual. Prefer. 2015, 40, 165-179. [CrossRef]

44. Roth, H.A.; Radle, L.J.; Gifford, S.R.; Clydesdale, F.M. Psychophysical relationships between perceived sweetness and color in lemon- and lime-flavored drinks. J. Food Sci. 1988, 53, 1116-1119. [CrossRef]

45. Hutchings, J.B. Expectations and the Food Industry: The Impact of Color and Appearance; Kluwer Academic/ Plenum Publisher: New York, NY, USA, 2003.

46. Delwiche, J. The impact of perceptual interactions on perceived flavor. Food Qual. Prefer. 2004, 15, 137-146. [CrossRef]

47. Morrot, G.; Brochet, F.; Dubourdieu, D. The color of odors. Brain Lang. 2001, 79, 309-320. [CrossRef] [PubMed]

48. Spence, C. On the psychological impact of food colour. Flavour 2015, 4. [CrossRef]

49. Berryman, D. The use of fruit juices as natural colouring agents. New Food Beverage Process. Suppl. 2014, 17, $25-29$.

50. Keast, R.S.J.; Costanzo, A. Is fat the sixth taste primary? Evidence and implications. Flavour 2015, 4, 1-7. [CrossRef]

51. Spence, C. Multisensory flavour perception. Curr. Biol. 2013, 23, R365-R369. [CrossRef] [PubMed]

52. Dalton, P.; Doolittle, N.; Nagata, H.; Breslin, P.A.S. The merging of the senses: Integration of subthreshold taste and smell. Nat. Neurosci. 2003, 3, 431-432. [CrossRef] [PubMed]

53. Clark, J.E. Taste and flavour: Their importance in food choice and acceptance. Proc. Nutr. Soc. 1998, 57, 639-643. [CrossRef] [PubMed]

54. Steiner, J.E. Facial expressions of the neonate infant indicating the hedonics of food related chemical stimuli. In Taste and Development: The Genesis of Sweet Preference; DHEW Publication No. NIH 77-1068; United States Department of Health, Education, and Welfare: Bethesda, MD, USA, 1977; pp. 173-189.

55. Spence, C.; Levitan, C.; Shankar, M.U.; Zampini, M. Does food color influence taste and flavor perception in humans? Chemosens. Percept. 2010, 3, 68-84. [CrossRef]

56. Stevenson, R.J. The Psychology of Flavour; Oxford University Press: Oxford, UK, 2009.

57. Fallico, B.; Arena, E.; Chiappara, E.; Ballistreria, G. Colour and label evaluation of commercial pasteurised red juices and related drinks. Food Addit. Contam. B Surveill. 2010, 3, 201-211. [CrossRef] [PubMed] 
58. McGorrin, R.J. The significance of volatile sulfur compounds in food flavors: An overview. In Volatile Sulfur Compounds in Food; ACS Symposium Series; American Chemical Society: Washington, DC, USA, 2011.

59. Goeke, A. Sulfur-containing odorants in fragrance chemistry. Sulfur Rep. 2002, 23, 243-278. [CrossRef]

60. Boelens, M.H.; van Gemert, L.J. Volatile character-impact sulfur compounds and their sensory properties. Perfum. Flavorist 1993, 18, 29-39.

61. Darriet, P.; Lavigne, V.; Boidron, J.; Dubourdieu, D. Identification of a powerful aromatic component of Vitis. vinifera L. var. Sauvignon Wines: 4-Mercapto-4-methylpentan-2-one. Flavour Fragr. J. 1995, 10, 385-392. [CrossRef]

62. Kolor, M.G. Identification of an important new flavor compound in Concord grape: ethyl-3-mercaptopropionate. J. Agric. Food Chem. 1983, 31, 1125-1127. [CrossRef]

63. Schulbach, K.F.; Rouseff, R.L.; Sims, C.A.J. Changes in Volatile Sulfur Compounds in Strawberry Puree during Heating. Food Sci. 2004, 69, FCT268-FCT272. [CrossRef]

64. Boccorh, R.K.; Paterson, A.; Piggot, J.R. Extraction of aroma components to quantify overall, sensory character in a processed blackcurrant (Ribes nigrum L.) concentrate. Flavour Fragr. J. 2002, 17, 385-391. [CrossRef]

65. Varming, C.; Petersen, M.A.; Poll, L.J. Comparison of isolation methods for the determination of important aroma compounds in black currant (Ribes nigrum L.) juice, using nasal impact frequency profiling. Agric. Food Chem. 2004, 52, 1647-1652. [CrossRef] [PubMed]

66. Gerber, N.N. Three highly odorous metabolites from an Actinomycete: 2-isopropyl-3-methoxypyrazine, methylisoborneol and geosmin. J. Chem. Ecol. 1977, 3, 475-482. [CrossRef]

67. Splittstoesser, D.F. Microorganisms involved in the spoilage of fermented fruit juice. J. Food Protect. 1982, 45, 874-877.

68. Bevilacqua, A.; Corbo, M.R.; Campaniello, D.; D’Amato, D.; Gallo, M.; Speranza, B.; Sinigaglia, M. Shelf life prolongation of fruit juices through essential oils and homogenization: A review. In Science against Microbial Pathogens: Communicating Current Research and Technological Advances; Méndez-Vilas, A., Ed.; Formatex Research Center: Badajoz, Spain, 2011; Microbiology Series No 3; Volume 1, pp. 1157-1166.

69. Siegmund, B.; Pöllinger-Zierler, B. Odor thresholds of microbially induced off-flavor compounds in apple juice. J. Agric. Food Chem. 2006, 54, 5984-5989. [CrossRef] [PubMed]

70. Maga, J.A. Compound structure versus bitter taste. In Bitterness in Foods and Beverages. Developments in Food Science; Rousseff, R.L., Ed.; Elsevier: Amsterdam, The Netherlands, 1990; Volume 25, pp. 35-48.

71. Schobinger, U. Frucht-und Gemüsesäfte, Handbuch der Lebensmitteltechnologie; Verlag Eugen Ulmer: Stuttgart, Germany, 2001; pp. 506-635.

72. Billing, J.; Sherman, P.W. Antimicrobial function of spices: Why some like it hot. Q. Rev. Biol. 1998, 73, 3-49. [CrossRef] [PubMed]

73. Bravo, L. Polyphenols: Chemistry, dietary sources, metabolism, and nutritional significance. Nutr. Rev. 1998, 56, 317-333. [CrossRef] [PubMed]

74. Ames, B.N.; Profet, M.; Gold, L.S. Dietary pesticides (99.99\% all natural). Proc. Natl. Acad. Sci. USA 1990, 87, 777-781. [CrossRef]

75. Scalbert, A. Antimicrobial properties of tannins. Phytochemistry 1991, 30, 3875-3883. [CrossRef]

76. Rouseff, R.L. Bitterness in food products: An overview. In Bitterness in Foods and Beverages. Developments in Food Science; Rousseff, R.L., Ed.; Elsevier: Amsterdam, The Netherlands, 1990; Volume 25, pp. 1-14.

77. Fenwick, G.R.; Curl, C.L.; Griffiths, N.M.; Heaney, R.K.; Price, K.R. Bitter principles in food plants. In Bitterness in Foods and Beverages. Developments in Food Science; Rousseff, R.L., Ed.; Elsevier: Amsterdam, The Netherlands, 1990; Volume 25, pp. 205-250.

78. Mikkelsen, B.B.; Poll, L. Decomposition and transformation of aroma compounds and anthocyanins during black currant (Ribes nigrum L.) juice processing. J. Food Sci. 2002, 67, 3447-3455. [CrossRef]

79. Laaksonen, O.; Sandell, M.; Nordlund, E.; Heiniö, R.-L.; Malinen, H.-L.; Jaakkola, M.; Kallio, H. The effect of enzymatic treatment on blackcurrant (Ribes nigrum) juice flavour and its stability. Food Chem. 2012, 130, 31-41. [CrossRef]

80. Laaksonen, O.; Ahola, J.; Sandell, M. Explaining and predicting individually experienced liking of berry fractions by the hTAS2R38 taste receptor genotype. Appetite 2013, 61, 85-96. [CrossRef] [PubMed]

81. Ng, M.; Lawlor, J.B.; Chandra, S.; Chaya, C.; Hewson, L.; Hort, J. Using quantitative descriptive analysis and temporal dominance of sensations analysis as complementary methods for profiling commercial blackcurrant squashes. Food Qual. Prefer. 2012, 25, 121-134. [CrossRef] 
82. Verbeke, W. Functional foods. Consumer willingness to compromise on taste for health? Food Qual. Prefer. 2006, 17, 126-131. [CrossRef]

83. Muir, D.D.; Hunter, E.A.; Williams, S.A.R.; Brennan, R.M. Sensory profiles of commercial fruit juice drinks: Influence of sweetener type. J. Agric.Food. Chem. 1998, 77, 559-565. [CrossRef]

84. Laaksonen, O.; Mäkilä, L.; Tahvonen, R.; Kallio, H.; Yang, B. Sensory quality and compositional characteristics of blackcurrant juices produced by different processes. Food Chem. 2013, 138, 2421-2429. [CrossRef] [PubMed]

85. Laaksonen, O.A.; Mäkilä, L.; Sandell, M.A.; Salminen, J.-P.; Liu, P.; Kallio, H.P.; Yang, B. Chemical-sensory characteristics and consumer responses of blackcurrant juices produced by different industrial processes. Food Bioprocess. Technol. 2014, 7, 2877-2888. [CrossRef]

(C) 2016 by the authors; licensee MDPI, Basel, Switzerland. This article is an open access article distributed under the terms and conditions of the Creative Commons Attribution (CC-BY) license (http://creativecommons.org/licenses/by/4.0/). 